\title{
Factors Affecting Exclusive Breastfeeding Practice in Rural Communities of Cross River State, Nigenia
}

\author{
Ella, R.E \\ Ph. D, M. ed, Bsc. RN, RM, RNT, CHPM, FWACN \\ Department of Nursing University of Calabar \\ retila07@yahoo.com \\ Ndep, A.O \\ DrPH, MPH, Bsc, CHES \\ Department of Public Health, University of Calabar
}

Akpan, M. I

RN, RM Bsc, MPH, FWACN

Department of Nursing, University of Calabar

\begin{abstract}
Breastfeeding rates among rural African women steadily declined during the 1960's. The introduction of exclusive breast feeding (EBF) in the 80 s helped reduce infant morbidity/mortality however, misconceptions about when to initiate EBF and for how long still persists till date.

Objective: To determine factors associated with exclusive breastfeeding in Kakwagom and Okundi communities in Boki L.G.A of Cross River, Nigeria.

Methods: A self-administered questionnaire was administered to 366 mothers selected through simple random sampling.

Results: Of the 366 respondents, 189 (51.64\%) were between the ages of $31-40 ; 303$ (82.79) were married and $78.42 \%$ had secondary education. About $84 \%$ had good knowledge of EBF, of these $47 \%$ had this knowledge from antenatal. Chi square $\left(x^{2}\right)$ analysis revealed significant relationship between mothers' knowledge and exclusive breastfeeding practices $(P<0.05)$. Almost $83 \%$ had positive attitude towards EBF yet only $14.6 \%$ mothers practiced EBF. Factors that hinderedEBF practice were job conditions (48.9\%), inadequate breast milk (11.48\%), sore nipple (8.74\%), and stress (14.75\%).
\end{abstract}

Conclusion: Social support and workplace policies promoting EBF could encourage EBF practice which could then translate to the positive health effects for both mothers and children.

Ke ywords: Exclusive breastfeeding, factors, hindrances, practice, rural communities.

\section{BACKGROUND}

Breast feeding is an integral part of the reproductive process with important implications for the health of the mother and baby (Essien and Sampson-Akpan 2013). Exclusive Breast Feeding (EBF) is when an infant is given its entire nutrient from human breast milk and receives no complementary food during the first six months of birth. Thereafter, infants should receive complimentary food with continued breast feeding up to two years of age and beyond.EBF for the first 6 months of life followed by optimal complementary feeding are critical public health measures for reducing and preventing morbidity and mortality in young children because breastfeeding supports infants' immune systems and helps protect them from chronic conditions later in life such as obesity and diabetes(Ojong, Chiotu, and Nlumanze 2015). According to UNICEF, 10 million deaths in under- 5 children were recorded in 2006, of which 4 million died within the $1^{\text {st }}$ month of life and half within the first 24 hours ( Onah, Osuorah, Ebeneche, J., Ezechuckwu, Ekwochi, \& Ndukwu (2014).). These mortality rates could have been reduced to the barest minimum through support to mothers to practice EBF.A Nigerian national survey done in 2008 showed that EBF rates still remain very low (13\%) (Onah et al., 2014). Exclusive breastfed infants are much less likely to die from diarrhea, acute respiratory infections and other diseases. They are healthier, have fewer hospitalizations, and lower mortality rates than formula fed infants (Ajayi, Hellandendu and Odekunle 2011). 
The success of EBF has been attributed to several factors such as provision of accurate information, support to breast feeding mothers and perception (beliefs and attitude) of mothers, (Wambach, Campell, Gill, Datgston, Abiona, \& Heing, 2005, Edegbai, 2001). The role of the health care professional is critical in providing women with the information they need to make them accept and practice EBF. Edegbai (2001) reported that health information and education significantly influenced mothers' knowledge and practice of EBF.

Oyewo and Taiwo (2010) explored knowledge and awareness of exclusive breastfeeding among mothers in Lagos, Nigeria. The researchers made use of the survey method and tried to balance responses to a 20 item questionnaire with qualitative data obtained through sessions with 4 focus groups. The result showed high level knowledge and awareness of exclusive breastfeeding among nursing mothers in both rural and urban areas of Lagos. This could be attributed to the increase creation of awareness that exits in urban cities in Nigeria, such as Lagos. In a related study conducted by Okolo, Adewunmi and Okonji (2009) to examine current breastfeeding knowledge, attitude, and practices of mothers in five rural communities in Toto Local Government in Nassarawa State, Nigeria, it was revealed that although breastfeeding was widely practiced among mothers, none of their babies was exclusively breastfed, and pre-lacteal feeds ranging from water, formula, or herbal tea were given by all the mothers. This was an indication that the mothers had low level knowledge of exclusive breastfeeding practice and this can affect their attitude for EBF.

Successful breast feeding depend not only on a willing mother, a healthy infant, or encouragement by medical personnel, but also on attitude and beliefs about breast feeding developed by mothers. Research have shown that mothers with poor knowledge of EBF exhibit negative attitude about EBF and this accounts for the low rate of the practice (Nwachukwu and Nwachukwu 2007). While some mothers try to breast feed exclusively, most perceive exclusivebreastfeeding to be too difficult, stereos and tasking, and so resort to feeding their babies with infant's formula.

Wojcicki, Gugig, Tran, Kathiravan, Holbrook and Heyman, (2010) study on early exclusive breastfeeding and maternal attitudes towards infant feeding with new mothers at two San Francisco hospitals, using structured interview method revealed that a high percentage $(79.8 \%)$ of mothers exclusively breastfed their infant at a period of just 1-4 days postpartum. Mohammad,Yousef, Zouhair, \&Ahmad (2006) evaluated the knowledge,attitude and practice to breastfeeding as well as the factors associated with breastfeeding among women in the north of Jordan,the result showed that Jordanian women had positive attitude for breast feeding as was reflected in their thinking that breastfeeding was easier and less expensive than feeding infant withformula, but they exhibited negative attitude towards the practice of exclusive breastfeeding. Also Aniebue and Adioma (2010), evaluated the knowledge, beliefs and attitude of rural Nigeria women to EBF using a sample of 200 mothers from the rural community of Enugu-Nigeria, out of the 154 (82.4\%) that have heard of EBF only $29.9 \%$ knew the correct time for initiation of EBF. $30.5 \%$ believed that breast milk alone was not sufficient for the $1^{\text {st }}$ six months of life of an infant. 56.7\% accepted the practice of exclusive breastfeeding, only $38.5 \%$ accepted that colostrum is safe for a child. Reasons for rejecting colostrum were chiefly because it was perceived as poisonous, dirty milk and culturally unacceptable

Certain socio demographic variables such as age, marital status, level of education, occupation etc have been identified as barriers to the practice of Exclusive breast feeding. The result of Ajayi, Hellaidensis and Odekunle ( 2011) study in kogi state Nigeria revealed that mothers between the ages of 25-35 years practiced EBF more than women 15-24yrs. The researchers also identified mothers' educational level as a factor that can significantly affect the practice of EBF. The authors opined that most women who had formal education reside and work in the urban areas that have baby friendly hospitals. That these women were exposed to mass media and hand bills on EBF; these factors created awareness on the benefits of breast feeding, resulting in acceptance and practice of EBF. Educational level also affirmed by HBM and HPM as a factor that can influence the practice of health promoting behavior like EBF for the infants and mothers (Rosentock 1974, Pender, Murdaugh \& Parsons 2002).

Essien and Samson -Akpan (2013) study on EBF of women in Ikot Omin Cross River State revealed that $64 \%$ of the women who were married practiced $\mathrm{EBF}$, while $8.3 \%$ not married did not practice EBF. The result also revealed asignificant relationship between marital status and practice of EBF when the calculated $x^{2}$ of 27.8 was greater than critical $x^{2}$ of 9.48 with 4 degree of freedom. Grastner, Morton, Lawrence \& Naylor (2006) and Rosen stock (2000), affirmed that Fathers have an important 
influence on maternal decision in relation to EBF. In Africa and in Nigeria in particular, husbands play a very significant role in decision making and overall provision for the family. They most often decide how the family income should be spent. Hence their support to the practice of EBF is very vital. This calls for the total involvement through awareness creation of the benefits of EBF to not only mother but to significant others especially husbands who are the chief providers and decision makers. However, Bhavana. (2010) study on knowledge, attitude and practice of breast feeding - a case study of Kumasi, Ghana examined the relationship betweeneducational level, age, marital status and occupation and duration of breast feeding among mothers. The findings of the study showed that: $16.6 \%$ of unmarried women breast fed their babies for less than 6 months as compared to only $2.6 \%$ of married women.

Breastfeeding a baby at least once every 2-3 hours encourages constant supply of milk and breast feeding 8 times a day tends to facilitate copious milk supply in most women during the $1^{\text {st }} 4$ months or more after delivery. Many employed mothers find it difficult meeting up with the above requirement of EBF, if the nature of their job does not allow them the opportunity (Essien and Samson Akpan 2013). Also some employers do not encourage working mothers optimal exclusive breast feeding practice after the end of maternity level, because they do make provisions for nursing mothers to have breaks to allow them to breast feed their babies. Mohammad, et al (2006) discovered that employed women were more likely not to practice exclusive breastfeeding compared to unemployed women.

Several studies have identified negativeattitudes of health care providers and lack of social support as barriers to successful infant feeding practices. Friendly attitude of health workers, having friends who successfully breast feed increases the likely hood of another breast feeding. The study of Aghaji (2007) on EBF practice and associated factors in Enugu, Nigeria, revealed among other things that low income and family opposition especially from grandparents hindered EBF practice. Low economic status mothers and middle class mothers' breast fed their babies for less than 6 months as compared to high income mothers. In contrast the study of Scott and Binns (2004) on socio-economic factors and exclusive breast feeding revealed that among the 215 women studied, $78 \%$ who were low income earners practiced EBF longer than $49.4 \%$ of high income earners that had difficulty. Some studies also report that mothers found exclusive breastfeeding to be physically strenuous and uncomfortable.

It is an established fact that EBF has yielded tremendous benefits in the reduction of child mortality rates in Africa and Nigeria in particular. However, despite the benefits and some improvements in child mortality rate in Africa, much still remains to be done because neonatal mortality has remained the same or worsened in some countries. According to UNICEF, 10 million deaths in under- 5 children were recorded in 2006, of which 4 million died within the $1^{\text {st }}$ month of life and half within the first 24 hours (Onah et al., 2014).These mortality rates can still be reduced to the barest minimum through adherence of mothers to EBF. A Nigerian national survey done in 2008 showed that EBF rates still remain very low (13\%) (Onah et al., 2014). This is thought to be due to several factors associated with mothers' lack of proper education and supportive environments.Furthermore no study on EBF in cross river state has been carried out in these communities despite the high rate of infant mortality observed. This study aimed at investigating the factors affecting exclusive breastfeeding practice in Kakwagom and Okundi communities, of Boki Local Government Area of Cross River State, Nigeria

\section{PURPOSE OF THE STUdY}

The study was designed to investigate the factors that affect exclusive breastfeeding practice among mothers in Kakwagom and Okundi communities, of Boki Local Government Area of Cross River State.

\section{THE SPECIFIC OBJeCTIVES WeRE}

- To ascertain mothers level of knowledge on exclusive breast feeding in Okundi and kakwagom communities.

- To investigate mothers perception (beliefs and attitudes) towards exclusive breastfeeding in Okundi and Kakwagom communities.research questions and one hypothesis

- To determine the factors that hinder the practice of exclusive breastfeedingmothers among mothers in Kakwagom and Okundi communities 


\section{RESEARCH QUESTIONS}

- What is the level of knowledge on exclusive breast feeding in kakwagom and Okundi communities

- What are the attitudes of mothers towards exclusive breastfeeding in Kakwagom and Okundi communities?

- What are the factors that hinder the practice of exclusive breast feeding among in Kakwagom and Okundi communities

\section{HYPOTHESIS}

- There is no significant relationship between mothers level of knowledge and their practice of exclusive breast feeding in Kakwagom and Okundi communities.

This study covers all mothers with children 0-3 years of age, attending ante- or post-natal clinics at Kakwagom and Okundi communities of Cross River state.

\section{Methodology}

\subsection{Study Design}

The research design adopted for the study was a cross sectional descriptive survey.

\subsubsection{Research Setting}

The study was carried out in Kagwagom and Okundi communities which are located in the western part of Boki Local Government Area, (Boki LGA is one of the 18 LGAsand is in the Central Senatorial District) of Cross River State, Nigeria. Kagwagom and Okundi are the largest and most popular villages in Boki LGA, with the largest markets and secondary schools. They speak buki language and are predominantly farmers but house a lot of visitors who engage in spare parts business, trading and driving. The communities are semi-urban in nature. They are thickly populated and enjoy social amenities such as roads, electricity and portable water. The communities have about 4 health posts with two big primary health care centers, each at Kakwagom and Okundi. These centersserve as referral points for other smaller villages. On the average the centers maintains infant welfare clinics (in addition to other services)which runs twice in a week. They attend to 30-50 mother infant dyads on each clinic day, and provide mainly free routine immunization services. Other services include family planning, growth monitoring and counseling in other aspects of child survival strategiesand maternal health services.

\subsubsection{Study Population}

The target population comprised all mothers with children aged 0-3 years in Kagwagomand Okundi communities who usually visit these clinics for postnatal care services and for various types of immunizations for their babies. However, the accessible population of the study comprised one thousand, one hundred and nineteen (1119) mothers who took their children to Okundi and Kagwagom health centers for national immunization for poliomyelitis, from June $21^{\text {st }}$ to August $25^{\text {th }}$, 2014. A total sample of three hundred and thirty-six (336) mothers of children aged 0-3 year;, mothers whose babies were 4years and above, mothers of twin babies, HIV positive babies sick babies were not included

\section{RESEARCH INSTRUMENT}

A researcher made questionnairewas used. The questionnaire was made up of 2 sections. Part one designed to elicit socio-demographic data of the mothers and their children, Part two elicited information on mothers'Knowledge and practice of exclusive breast feeding. This was further divided into sub sections based on the research objectives such as level of mothers' knowledge on exclusive breastfeeding, attitude of mothers towards exclusive breastfeeding and factors that hinder exclusive breastfeeding practice among mothers. The test re-test reliability coefficient was $r 0.71$ to 0.83 which was considered adequate for the instrument to be used.

Face to face administration of the questionnaire was carried out by two researchers with two trained research assistants, for a period of two months. Completed copies of questionnaires were collected on spot. About 380 questionnaires were administered because some mothers who did not meet the inclusion criteria were curious to participate, however they were administered the questionnaire but only the 336 were analyzed. 


\section{ETHICAL CONSIDERATION}

Official permission was obtained from Boki Local Government Headquarters. Permission was also obtained from the village heads of the two communities and their respective gate keepers; this was done with the assistance of the two Primary Health Care coordinators in kakwagom and okundi villages. Informed consent was obtained from the participants after the purpose of the study was explained to them. Anonymity was maintained and it was strictly confidential.

\section{ReSULTS AND DisCUSSIONS}

\section{Socio-Demographic Data $\mathbf{n}=336$}

Table1. Socio-demographic data of the respondents by age, marital status, educational level and occupation

\begin{tabular}{|l|c|c|}
\hline Variables & Frequency & Percentage (\%) \\
\hline 1. Age & & \\
Below 21 yrs. & 71 & 19.40 \\
$21-30$ yrs. & 189 & 51.64 \\
$31-40$ yrs. & 106 & 28.96 \\
\hline Total & $\mathbf{3 6 6}$ & $\mathbf{1 0 0 . 0 0}$ \\
\hline 2. Marital Status & & \\
Single & 49 & 13.38 \\
Married & 303 & 82.79 \\
Divorce & 5 & 1.37 \\
Widow & 9 & 2.46 \\
\hline Total & $\mathbf{3 6 6}$ & $\mathbf{1 0 0 . 0 0}$ \\
\hline 3. Educational Level & & \\
No formal education & - & - \\
Primary education & 23 & 6.28 \\
Secondary education & 287 & 78.42 \\
Tertiary education & 56 & 15.30 \\
\hline Total & $\mathbf{3 6 6}$ & $\mathbf{1 0 0 . 0 0}$ \\
\hline 4. Occupation & & \\
Farmers & 102 & 27.87 \\
Civil servants & 89 & 24.32 \\
Busines & 73 & 19.95 \\
Students & 67 & 18.31 \\
Applicants & 35 & $\mathbf{1 0 0 . 0 0}$ \\
\hline Total & $\mathbf{3 6 6}$ & \\
\hline
\end{tabular}

Of the 366 mothers interviewed, $71(19.40 \%)$ were below 21 years and majority, $189(51.64 \%)$ were between 21-30 years. The marital status of respondents showed that $49(13.38 \%)$ of the respondents were single, $303(82.38 \%)$ were married, $5(1.37 \%)$ were divorced while $9(2.46 \%)$ were widows. Information on respondents' educational level revealed that $23(6.28 \%)$ had primary education, 287 (78.82\%) had secondary education while $56(15.30 \%)$ had tertiary education. Data on the occupation of respondents showed that $102(27.87 \%)$ of mothers were subsistent farmers. 89 (24.32\%) were civil servants, $73(19.95 \%)$ were petty traders, $67(18.31 \%)$ were students while $35(9.56 \%)$ were applicants.

\section{ReSUlt OF ReSEARCH QUESTIONS}

\subsection{Research Question One}

What is the level of mothers' knowledge on exclusive breastfeeding in Kakwagom and Okundi communities? Descriptive statistics was used for data analysis. The result of this analysis is presented in Figure 1

The result of data analysis presented in Figure 1 revealed that majority of the mothers $306(83.61 \%)$ had high know ledge level about exclusive breastfeeding and its definition while $60(16.39 \%)$ of mothers had low knowledge level about exclusive breast feeding (EBF). Those who had low know ledge also reported not knowing that EBF involves exclusively breastfeeding a baby in the first six months of life. 


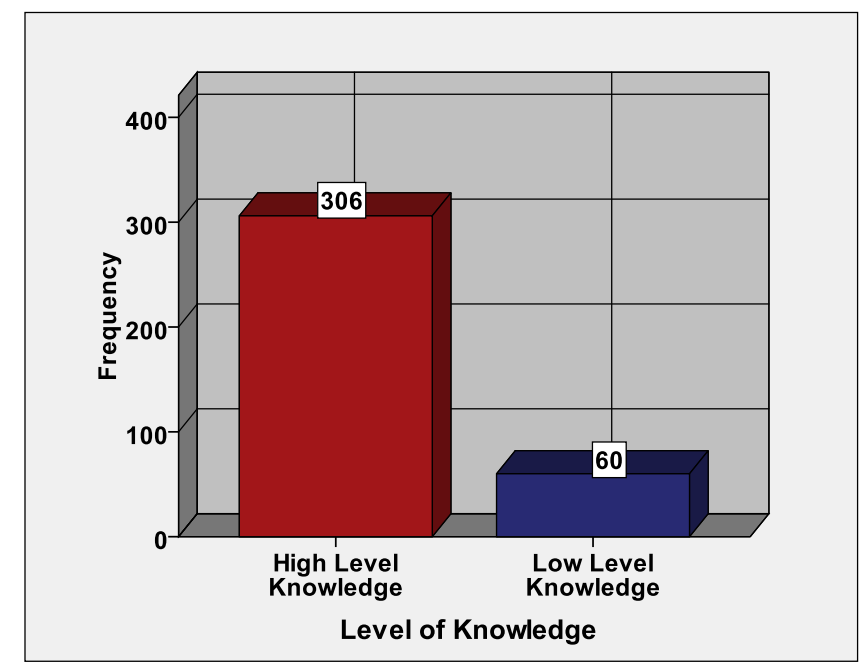

Figure1. Mothers' level of knowledge about exclusive breastfeeding in Kakwagom and Okundi communities in Boki Local Government Area, Cross River State.

\subsection{Research Question Two}

What are mothers 'perception(beliefs and attitudes)towards exclusive breastfeeding in Kakwagom and Okundi communities? Descriptive statistics was used for data analysis. The result of this analysis is presented in Figure 2.

Table2.Mothers' Responses to their beliefs and attitudes towards Exclusive Breastfeeding

\begin{tabular}{|l|l|l|l|l|}
\hline & Attitude towards EBF & Frequency & Total \\
\cline { 3 - 5 } & & Yes & No & \\
\hline 1 & EBF is stressfuland boring to mothers & $262(71.58)$ & $104(28.42)$ & 366 \\
\hline 2 & EBF causes excessive pains in the nipple & $148(40.44)$ & $218(59.56)$ & 366 \\
\hline 3 & EBF makes infants uncomfortable & $256(69.95)$ & $110(30.05)$ & 366 \\
\hline 4 & Makes the child very healthy & $201(54.90)$ & $165(45.10)$ & 366 \\
\hline 5 & EBF Leads to child malnourishment & $161(43.99)$ & $205(56.01)$ & 366 \\
\hline 6 & EBF is Less expensive & $366(100.00)$ & - & 366 \\
\hline
\end{tabular}

Note: Figures in brackets are in percentage.

Majority of the mothers, $262(71.58 \%)$ perceived exclusive breastfeeding to be stressful while 104 (28.42\%) mothers did not. Others, $148(40.44 \%)$ reported that the main barrier to EBF was excessive pains in the nipple, but a majority of $218(59.56 \%)$ did not. Almost $70 \%$ of mothers believed that EBF makes infants uncomfortable, whereas $110(30.05 \%)$ did not. Those that view EBF as positive and healthy for the baby were $201(54.90 \%)$, as against 165 (45.10) that did not. Almost $44 \%$ of mothers believed that EBF leads to child malnourishment. Majority of mothers 304 (83.06\%) had positive attitudes towards exclusive breastfeeding, and they acknowledged that the practice should be encouraged, while only $64(16.94 \%)$ mothers had negative attitude towards EBF.

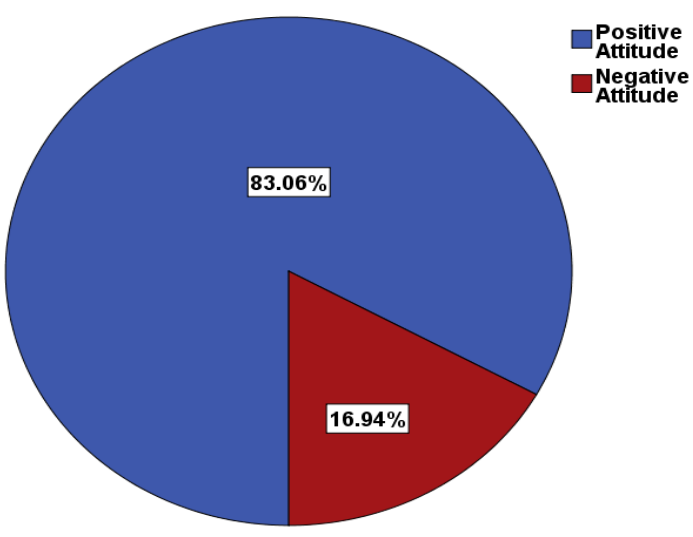

Figure2. Pie chart showing mothers' attitude towards exclusive breastfeeding in Okundi and Kakwagom communities in Boki Local Government Area, Cross River State. 
The result of data analysis presented in figure 2 showed that majority of mothers $\{304(83.06 \%)\}$ had positive attitude towards exclusive breastfeeding, as they acknowledged that the practice should be encouraged, while only $64(16.94 \%)$ mothers had negative attitude towards the practice of exclusive breastfeeding .

\subsection{Research Question 3}

What are the factors that hinder exclusive breastfeeding practice among mothers in Kakwagom and Okundi Communities?

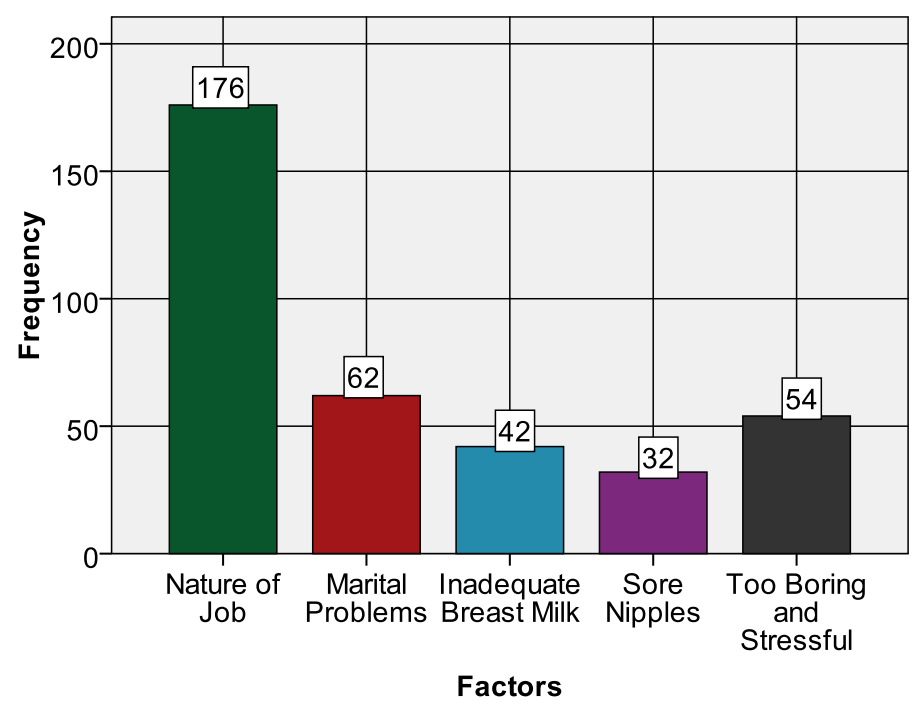

Figure3. Bar Chart showing factors that hinder exclusive breastfeeding practice among mothers in Kakwagom and Okundi Communities

The result of analys is presented in Figure 3 revealed that $176(48.09 \%)$ of mothers cited job conditions as the factor hindering their practice of exclusive breast feeding, 62 (16.94\%) mothers were hindered by marital problems. Those that said the breast milk was not enoughfor the babies were $42(11.48 \%)$ and $32(8.74 \%)$ developed sore nipples so they could not exclusively breastfeed their babies, while the remaining $54(14.75 \%)$ mothers see exclusive breastfeeding as too boring and stressful.

\section{TEST OF HYPOTHESES}

\section{Hypothes is 1}

There is no statistically significant relationship between level of knowledge and exclusive breastfeeding practice among mothers in Kakwagom and Okundi Communities.

Table4.Cross tabulation ofMothers' Knowledge about Exclusive Breast Feeding and Breastfeeding practice

\begin{tabular}{|l|l|l|l|}
\hline \multirow{2}{*}{ Level of Knowedge } & \multicolumn{2}{|l|}{ Exclusive Breastfeeding practice } & \multirow{2}{*}{ Total } \\
\cline { 2 - 3 } & Practiced EBF & Did not Practice EBF & \\
\hline High Level Knowledge & 49 & 257 & 306 \\
Expected Count & $(41.0)$ & 265.0 & 306.0 \\
\hline Low Level Knowledge & 0 & 60 & 60 \\
Expected Count & 8.0 & 52.0 & 60.0 \\
\hline Total & 49 & 317 & 366 \\
& 49.0 & 317.0 & 366.0 \\
\hline
\end{tabular}

Significant at 0.05; $d f=1 ;$ Critical $X^{2}=3.84$; Calculated Pearson Chi-Square $=11.538$

The result obtained from analysis of hypothesis showed that the calculated $\mathrm{X}^{2}$ value of 11.538 is higher than the critical $\mathrm{X}^{2}$ value of 3.84 at 0.05 level of significance with1 degree of freedom. Hence the null hypothesis that there is no significant relationship between level of knowledge and exclusive breastfeeding practice among mothers in Kakwagom and Okundi Communities was rejected. This means that there is significant relationship between level of knowledge and exclusive breastfeeding practice among mothers. 


\section{DISCUSSION}

The study revealed that majority of the respondents 189 (51.64) were between the ages of $21-30$ years. Also, majority 303 (82.79) were married and $287(78.42 \%)$ had secondary education as their highest level of education. In addition, majority $102(27.87 \%)$ of the mothers' were farmers, followed by civil servants and business women.Majority of them had a high level of knowledge about exclusive breastfeeding, but only a few practiced it. This finding is not surprising because knowledge is not synonymous to practice (Bhavana, 2010.Okon, 2015; Oyewo \& Taiwo, 2010). Having knowledge of a thing can be hindered from putting the knowledge to action by certain believes, lack of support and lack of recourses.

Mothers believed that EBF makes a child to be very healthy, yet still some believed that EBF causes malnourishment in children. This findings seems contradictory but can be justified, considering mothers overall responses. Though they believed that EBF makes a children, healthy yet babies of some mothers were so healthy which could be a pointer to lack proper education, and lack of support for mothers to feed and drink (water) properly to make their babies healthy, hence the issue of malnourishment. For EBF to be successful mothers need, to be proper informed of the benefits of $\mathrm{EBF}$, they also need support from their husbands and significant others to eat balanced diet and drink well.

Furthermore, the result revealed thatjob conditions or nature of their jobs was a major factor responsible for mothers' inability to practice exclusive breastfeeding. Not surprising because majority of mothers were farmers and EBF is difficult to practice byfarmers especially with no support from family members. Mohammed et al (2006) findings that employed women did not practice exclusive breastfeeding compared to unemployed women supports this result. The majority of mothers in this setting were self employed (farmers) while some were civil servants. Therefore mothers were hindered by their jobs of farming or office work. For EBF to be effective and sustained for up to six months mothers need both physical and emotional support from significant others such their husbands, in-laws, friends and counselors and support from their employees.

Others factors were marital problems, inadequate breast milk, sore nipples resulting from excessive breast-sucking, and the stress/boredom associated with regular breastfeeding of babies. Considering the communities in question these factors could be anticipated because most often mothers leave earlyto theirfarms carrying their babies without eating or drinking and engage in farm work for long hours before thinking of breakfast or water. This could be responsible for the inadequate flow of breast milk. Inadequate flow could cause lack of satisfaction to the infant thus long suck before satisfaction. This long suck mayresult to sored and painful nipples. The unhygienic process of breast feeding the infant since they do not take time to clean up the nipples while in the ir farms or because they lack the know- how before breastfeeding could result to serious infection and death hence the highinfant mortality.

Also women in these rural communities hardly engaged any support or helps for themselves or for the sake of their babies. Activities of a married mother are most often carried out singly. They perceive that only mothers with white collar jobs deserve to have helps as such. Not surprising therefore that they find breast feeding to be stressful and boring because the task of farm work as engaged by majority of the mothers coupled with that of babysitting could be physically and emotionally stressful. Bhavana (2010) supports the result that lack of adequate support results to negative attitude or dislike for breast feeding practice.

It is not surprising that these women despite their high level of knowledgeand positive attitude for EBF did not successfully practice EBF because the various hindrances, attest to the fact that knowledge does not translate to practice. Others supportive machineries have to be put in place to ensure change of attitude and effective practice of EBF in Kakwagom and Okundi communities.

\section{CONCLUSION}

This study revealed that mothers in Okundi and Kakwagom communities, Boki LGA, had a high level knowledge about exclusive breastfeeding, held varying beliefs regarding exclusive breastfeeding practice and exhibited positive attitude towards the practice. However, despite high level know ledge and positive attitude exhibited by the mothers, exclusive breastfeeding practice among them was very low as a high proportion of the mothers could not exclusively breastfeed their babies. This was 
attributed to various factors, especially the nature of their jobs. Other factors such asmarital problems, inadequate breast milk from mothers, sore nipples resulting from excessive breast-sucking, and the stress/boredom associated with regular breastfeeding of babies

\section{RECOMMENDATIONS}

It istherefore recommended that: Breast feeding support groups should be established so that on discharge from hospital or clinic, mothers would be referred to them for proper orientation on exclusive breastfeeding practice.

- Since women are farmers they should have support from relations at the farms.

- Men could serve as veritable tools in the campaign for exclusive breastfeeding practice in the society. Husbands and in-laws should be involved especially in terms of provision good feeding for mothers and physical support

- Teenage boys who are potential fathers and men need to be educated on the need to support and encourage their wives to exclusively breastfeed their babies and to feed well.

- Health workers should intensify efforts at continuously informing all pregnant women about the benefits of exclusive breastfeeding, as well as show mothers how to carry out exclusive breastfeeding and how to maintain lactation even if they should be separated from their infants by going to farm or office work.

- Policies should be put in place to provide nursing mothers with favorable working conditions that would provide them with shorter working days with full pay, after they return from post natal/maternity leave. This will help to reduce decline of exclusive breastfeeding practice resulting from employment. To achieve this, Government should educate employers of labour on the need for post natal/maternal leave, to allow mothers the opportunity to exclusively breastfeed their babies.

\section{REFERENCES}

Afghani M.N. (2007) Exclusive breast feeding practice and associated factors in Enugu, Nigeria.West African Journal of Medicine 31(1), 66-69

Ajayi, A. D., Hellandensis, J, \& Odekule, F. (2011) Socio-demographic correlates of breast feedingPractices among mothers in Kogi State, Nigeria. West African Journal of Nursing. 22(1), 28-35.

Bhavana, S. (2010). Know ledge, attitude and practice of breast feeding - a case study of kumasi, ghana. European Journal of Scientific Research, 40(3), 404-422.

Edegbai, B. (2001), Influence of health information and education on lactation among mothers attending post natal clinics of family health centres. Abeokuta: Nigerian school health Journal 10(1).

Essien, N. C., and Samson-Akpan, P.E. (2013) Factors Influencing the practice of exclusive breastfeeding among women in Ikot Omin, Calabar, Nigeria. Mary Slessor Journal of Medicine. 12(1) $51-63$

Gastner, L., M;Morton, J., Lawrence, R. A., \& Laylor, A.J.. (2006) Breastfeeding and the use of human milk peadiatrics $115(2), 496-502$.

Nwachukwu, A.E. \& Nwachukwu, A. U. (2007) Common factors responsible for less than six months period of exclusive breast feeding among women in Nigeria.Journal of International Council for health physical education, recreation sports and dance (JCHPER-SD), 43(2), 30-35

Mohammad, K., Yousef, K., Zouhair, A.\&Ahmad, A. (2006). Practice, knowledge, attitude and factors associated with breastfeeding among women in the north of Jordan. International breastfeedingJournal1:17.

Ojong,N. I, Chiotu, C. N., Nlumanze, F.F. (2015) Factors Influencing the Practice of Exclusive Breastfeeding among Mothers in Tertiary Health Facilities in Calabar, Cross River State, Nigeria. American Journal of Nursing Science 4(1) 16-21 
Okolo, S.N; Adewunmi Y, B,\& Okonji, M.C. (2009). Current Breast feeding Knowledge, attitude and practices of mothers in five rural communities in the savannah regionn o Nigeria. Indian $\mathrm{J}$ Trop Peditatr 55(3)183-188.

Okon, E.B. (2015). Factors affecting exclusive breastfeeding practice in ikom town, cross river state, nigeria. Bachelor of Public Health), University of Calabar.

Onah, S., Osuorah, D.I.C., Ebeneche, J., Ezechuckwu, C., Ekwochi, U., \& Ndukwu, I. (2014). Infant breastfeeding practices and maternal socio-demographic factors that influence practice of exclusive breastfeeding among mothers in nnewi south -east nigeria. International breastfeeding Journal 9(6).

Oyewo, T.O., \& Taiwo, N. (2010). Exclusive breastfeeding in lagos: An awareness case study. Mass Communicator, 4(2), 20-29.

Pender, N. J., Murdaugh, C.L., \& Parsons, M.A. (2002). Health Promotion Model ( Revised). $4^{\text {th }}$ ed.Prentice Hall: New Jersey.

Rosenstock,I M. (1974). Historical Origin of Health Belief Model. In Becker, M. H eds. The Health Belief Model and personal health behaviour. Charles B Slack. Thorfare, New Jersey.

Scott, J.A and binns, C. W.(2004) Factors associated with initiation and duration of breast feeding. Breast feeding Review 7(1),5-15.

Wambach, K., Campell, S.H., Gill, S. L., Datgston, J. E., Abiona, T.C \& Heing, M. J, (2005) Clinical Lactation practices: 20 years of evidence. Journal of Human Lactation, 21(3): 245-258.

Wojc icki, J.M., Gugig, R., Tran, C., Kathiravan, S., Holbrook, K., \& Heyman, M.B. (2010). Early exclusive breastfeeding and maternal attitudes towards infant feeding in a population of new mothers in san francisco, california. Breastfeeding Med. Journal, 5(1), 9-15.

\section{AUTHORS' BIOGRAPHY}

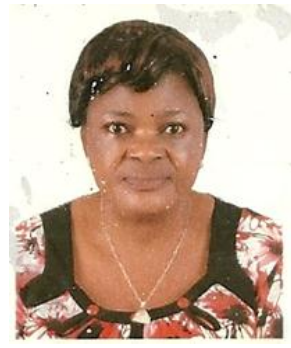

Regina E. Ella is a Nigerian Registered Nurse/Midwife with B. Sc Nursing; $\mathrm{M} . \mathrm{Ed}$ and $\mathrm{Ph}$. D with specialization in Educational Administration and Planning. She currently works as a senior lecturer with the University of Calabar. She has worked with the Cross River State Government as Secretary and Coordinator of the State Agency for Aids Control; as Palliative Care Advisor with CEDPA on HIV/AIDS Positive Living Project; Consultant trainer on HIV/AIDS Palliative Care with MSH. She is a Master trainer of trainers with CEDPA on HIV/AIDS Palliative Care. Her areas of interest are Nursing Education and HIV/AIDS. Dr Ella is a Fellow of The West Afriacn College of Nursing (WACN). A member of International Council for Nurses, member of the Honor society of Nursing (STTI) LAMDA Nigerian Chapter, and Member of American Public Health Association (APHA)

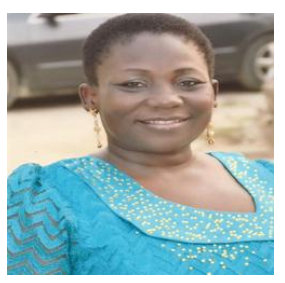

Dr. Antor Ndep, earned her B.Sc. in Physiology at the College of Medical Sciences in University of CalabarNigeria. She later earned her MPH (Maternal and Child Health) and DrPH (Health Education \& Communication) from Tulane University School of Public Health and Tropical Medicine in 2000 and 2010 respectively. Through those years she has worked as a Community Organizer, Public Health Administrator, and advocate for health literacy while teaching and supervising both graduate and undergraduate Public Health Students. Dr. Ndep is the innovator and co-author of Healthy Tales ${ }^{\mathrm{TM}}$, a unique health education tool aimed at people with low literacy. Her passion is to create change in communities by engaging in and promoting community participatory research and interventions. She is a proud Ejagham woman who is blessed with two biological children and many geographical, economic, educational and social children.

Mrs Margaret Inemesit, Akpan is a nurse clinician (Clinical intrsructor ) in the Department of Nursing Science uUniversity of Calabar. She is aregistered nurse midwife and holds a Bsc Nursing degree and a masters degree in public health and currently on a field work for her $\mathrm{Ph} . \mathrm{D}$ in public health. $\mathrm{S}$ he is also a fellow of West African College of Nursing (FWACN). Her areas of interest include research, community services and disease prevention. 